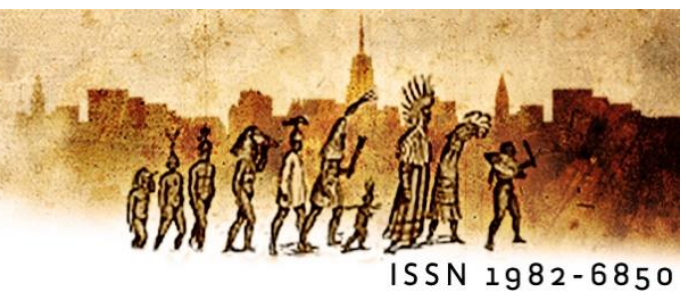

\title{
Orientações do pensamento bakhtiniano para uma postura pedagógica transformadora
}

\section{Bakhtinian thought guidelines for a transforming pedagogical posture}

Resumo: Este trabalho faz uma breve reflexão teórica sobre o pensamento bakhtiniano (BAKHTIN, 1997, 2002, 2003, 2016) e como ele pode orientar uma postura pedagógica voltada para uma educação transformadora, tendo como base a interação verbal e o diálogo. Nessa educação, o dialogismo vai ao encontro das preocupações com a desconstrução do poder do professor como único "conhecedor e senhor da informação", abrindo espaço para uma educação com várias vozes. Abordamos algumas reflexões iniciais, passíveis de serem mais profundamente desenvolvidas, mas que apontam para a necessidade de compreender as salas de aula de uma perspectiva diferente dos métodos tradicionais de ensino, bem como a impossibilidade de qualquer palavra ser final, acabada, ao passo que novas maneiras de significar e novos significados são sempre desejáveis.

Palavras-chaves: Dialogismo; Sala de Aula; Educação.

Abstract: This paper is a brief theoretical reflection on how the Bakhtinian thought (BAKHTIN, 1997, 2002, 2003, 2016) can be configured as guidelines for a pedagogical posture aimed at a transformative education based on verbal interaction and dialogue. In this education, the dialogue will meet concerns with the deconstruction of the teacher's power as the only "knowledgeable master of information", opening space for an education with several voices. We address some initial reflections, which may be more deeply reviewed upon, but that already point to the need to understand classrooms in a different perspective from traditional teaching methods, as well as the impossibility of any word being ultimate, completed, while new ways to signify and new

Eutomia, Recife, 27(1): 293-306, Out. 2020 
meanings are always appreciated.

Keywords: Dialogism; Classroom; Education.

\section{Introdução}

Na base de toda a teoria de Mikhail Bakhtin (1997, 2002, 2003, 2016), está o conceito de dialogismo - todos os discursos que configuram uma determinada comunidade, cultura ou sociedade dialogam entre si, com os discursos que os antecederam, com os seus contemporâneos e com discursos futuros, uma vez que o "outro" para o qual se destina o discurso está sempre presente no seu processo de elaboração, influenciando decisivamente em sua forma e em seus sentidos. "Tudo é meio, o diálogo é o fim. Uma só voz nada termina e nada resolve. Duas vozes são o mínimo de vida, o mínimo de existência" (BAKHTIN, 1997, p. 253).

Isso é contraposto ao monologismo - perspectiva ou consciência transcendental que integra todas as práticas, ideologias, valores e desejos significantes que são considerados significativos, "[...] não endereçado a ninguém, uma expressão puramente individual de um pensamento para si mesmo" (BAKHTIN, 2016, p.118) - característica da filosofia da linguagem, da linguística e da estilística do início do século passado.

Semelhante à interpretação do monologismo por Bakhtin, para alguns professores, o conteúdo de uma aula é fechado e pode ser transmitido aos alunos por meio de exposições ou palestras. De certa maneira, eles veem o significado como um produto acabado, independente da compreensão dos alunos, isto é, o papel dos alunos, na visão desses professores, é descobrir o significado fechado na concepção do docente ou aceitar completamente o que o professor Ihes transmite.

Partindo dessas observações feitas com base na experiência de docência, o presente artigo faz uma breve reflexão teórica sobre como o conceito de dialogismo de Bakhtin (1997, 2002, 2003, 2016) se conecta a um repensar pedagógico da posição docente não aberta ao debate, podendo contribuir para desvelar sentidos nos papeis professor-aluno e discutir alternativas para questões didáticas.

Eutomia, Recife, 27(1): 293-306, Out. 2020 
Assim como Geraldi que promoveu o debate e a reflexão a respeito das obras e do legado teórico dos dois autores, nos trabalhos "Paulo Freire e Mikhail Bakhtin: O encontro que não houve" (2003/2004) e "A Linguagem em Paulo Freire" (2005), também aproximamos suas perspectivas, que "compartilham um ponto de partida: a dialogia como espaço de construção do humano" (GERALDI, 2005, p. 14). Contudo, trataremos aqui de algumas reflexões iniciais, passíveis de serem mais profundamente desenvolvidas, mas que apontam para a necessidade de compreender as salas de aula de uma perspectiva diferente dos métodos tradicionais de ensino, bem como a impossibilidade de qualquer palavra ser final, acabada, ao passo que novas maneiras de significar e novos significados são sempre desejáveis. "A vida, concebida como acontecimento ético aberto, não comporta acabamento e, portanto, não comporta solução e fixidez. Está na incompletude a energia geradora da busca da completude eternamente inconclusa" (GERALDI, 2003/2004, p. 48).

A primeira parte deste artigo aborda o contraste entre monologismo e o dialogismo sob a perspectiva de Bakhtin, na qual o enunciado tem seus significados e sentidos construídos na relação entre os sujeitos. A segunda parte se refere ao papel docente em uma abordagem dialógica, tendo como base a interação verbal e o diálogo em sala de aula.

\section{Diálogo enquanto fim}

Nos "Problemas da Poética de Dostoiévski", Bakhtin (1997, p.17) afirma que "a multiplicidade de vozes e consciências independentes e imiscíveis e a autêntica polifonia de vozes plenivalentes constituem, de fato, a peculiaridade fundamental dos romances de Dostoiévski". Aqui, Bakhtin desenvolveu os conceitos que viriam a representar muito de seu trabalho. O conceito de "polifonia" (advindo da música) é central para esta análise. Polifonia significa literalmente várias vozes. Bakhtin lê a obra de Dostoiévski como contendo muitas vozes diferentes, imersas em perspectivas singulares, e não subordinadas à voz do autor. Cada uma dessas vozes tem sua própria perspectiva, sua própria validade e seu próprio peso narrativo dentro do romance. 
O romance de Dostoiévski aparece como uma interação de perspectivas ou ideologias distintas, suportadas pelos diferentes personagens. Os personagens são capazes de falar por si mesmos, mesmo contra o autor: como se o outro falasse diretamente através do texto. O papel do autor é fundamentalmente alterado, porque o autor não pode mais monopolizar o "poder de significar". (BAKHTIN, 1997).

Do ponto de vista de Bakhtin (2002), o encontro de diferentes ideologias ocorre na história como o choque entre forças centrífugas e centrípetas. A primeira atua sobre as forças que separam os sistemas de significados, promovendo a descentralização, e a última tenta manter esses sistemas unidos.

(...) a estratificação e o plurilinguismo ampliam-se e aprofundam-se na medida em que a língua está viva e desenvolvendo-se; ao lado das forças centrípetas caminha o trabalho contínuo das forças centrífugas da língua, ao lado da centralização verbo-ideológica e da união caminham ininterruptos os processos de descentralização e desunificação. (BAKHTIN, 2002, p. 82).

A principal diferença entre monologismo, "discurso que não se dirige a ninguém e não pressupõe resposta" (BAKHTIN, 2016, p. 92), e dialogismo surge exatamente nesse ponto em que essas duas forças estão em jogo. Para Bakhtin (1997), o monologismo, termo que ele usa não apenas para descrever certas tendências na literatura, também caracteriza uma posição ideológica específica, bem como um modo de consciência: uma verdade definitiva, o apagamento do outro. Se "uma consciência e uma boca são totalmente suficientes para toda a plenitude do conhecimento: não há necessidade de uma multiplicidade de consciências nem há base para ela" (1997, p.80). Em um mundo monológico, tudo giraria em torno do indivíduo isolado, autoritário, que não acolhe a palavra do outro, em torno de sua "fé na autossuficiência de uma única consciência" (1997, p.82). Nesse mundo, o outro é tratado como um objeto, não como um sujeito independente. Em virtude disso, a ideia de outra pessoa "não pode ser representada. Esta é assimilada, polemicamente negada ou deixa de ser ideia" (1997, p.84). Bakhtin ainda escreve que tal qual o discurso, "a ideia é por natureza dialógica, ao passo que o monólogo é apenas uma forma convencional de composição de sua expressão, que se constituiu na base do monologismo ideológico da Idade Moderna" (1997, p.88).

Eutomia, Recife, 27(1): 293-306, Out. 2020 
Em contraste ao monologismo, Bakhtin (1997, p.43), acredita que outros tipos de discursos encorajam relações dialógicas, "fenômeno bem mais amplo do que as relações entre as réplicas do diálogo expresso composicionalmente" com a palavra de outra pessoa. Para Bakhtin (1997), "monólogo" e "diálogo" representam os polos de um continuum e não uma oposição estática - discursos diferentes podem exibir essas tendências em graus diferentes. Logo, a palavra "diálogo" num sentido amplo, isto é, não sendo simplesmente a comunicação em voz alta, de pessoas posicionadas frente a frente, mas toda e qualquer comunicação verbal.

\section{Diálogo e Conhecimento}

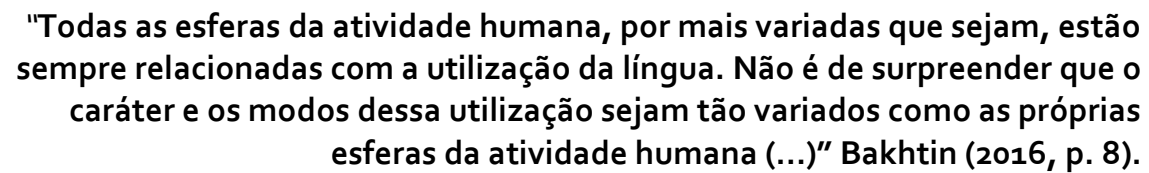

A nossa história mostra que a distância entre os povos vem diminuindo, graças a invenções que melhoraram a comunicação: a tipografia, o telefone, o rádio, a televisão. A internet, por sua vez, trouxe uma revolução sem precedentes na forma como nos comunicamos, deixando o planeta, de certa maneira, "menor". A internet é para muitos um meio confortável, se não o preferido, de pesquisa e comunicação. Com o advento de novas tecnologias e com a globalização dos mercados, a produção e o acesso às informações, cujo volume disponível para qualquer indivíduo vem crescendo exponencialmente nos últimos anos, tornaram-se algo ainda mais difundido e de rápido alcance. Algumas das consequências da transmissão dessas informações são a expressão, intercâmbio e divulgação entre diversas culturas pelo fenômeno social da interação discursiva, realizada através da enunciação ou das enunciações. Segundo Volóchinov (2017, p.52), "a interação discursiva é a realidade fundamental da linguagem", que se materializa em gêneros ${ }^{1}$.

Sejam orais, escritos, imagéticos ou até mesmo multifacetados, para Bakhtin (2016), os gêneros funcionam como práticas sociais, considerando-se que são compostos por enunciados relativamente estáveis, sócio-historicamente construídos. Isso implica que, enquanto produtos

\footnotetext{
${ }^{1}$ Bakhtin (2003, p.281), divide esses gêneros em primários (simples) e secundários (complexos). Os primários se manifestam em situações comunicativas cotidianas, espontâneas e informais; enquanto os secundários aparecem em situações comunicativas mais complexas, como uma peça de teatro, palestras etc.
}

Eutomia, Recife, 27(1): 293-306, Out. 2020 
das atividades de linguagem nas formações sociais, cada gênero é apropriado a sua especificidade, com finalidade discursiva e estilo correspondentes. Ainda segundo Bakhtin (2016), a diversidade desses gêneros é determinada por suas diferenças em função da situação, da posição social e das relações sociais de reciprocidade entre os participantes da comunicação.

Ademais, a linguagem na perspectiva de Bakhtin está centrada em enunciados dialógicos em oposição a estruturas gramaticais. Ele salienta que os problemas da visão formalista da linguagem resultam em ignorar o enunciado, que é a "real unidade da comunicação discursiva" (BAKHTIN, 2016, p. 28, grifos do autor), e delimitado pela alternância de sujeitos falantes. "O enunciado não é uma unidade convencional, mas uma unidade real, delimitada com precisão pela alternância dos sujeitos do discurso e que termina com a transmissão da palavra ao outro [...]" (BAKHTIN, 2016, p. 29). Nesse processo, o receptor não é passivo ao ouvir e compreender o enunciado, mas tem uma postura responsiva, podendo opinar, interromper, argumentar... Exercendo um papel ativo no ato comunicativo e, dessa maneira, caracterizando o enunciado.

(...) A fala só existe, na realidade, na forma concreta dos enunciados de um indivíduo: do sujeito de um discurso-fala. O discurso se molda sempre à forma do enunciado que pertence a um sujeito falante e não pode existir fora dessa forma. (BAKHTIN, 2016, p.22)

Como Bakhtin (2016) argumenta, um enunciado é dotado de expressividade e recebe sua significação em virtude de sua posição em uma cadeia de comunicação da fala, pois "todo enunciado é dialógico, ou seja, é endereçado a outros, participa do processo de intercâmbio de ideias: é social" (BAKHTIN, 2016, p. 118). Mais especificamente, do ponto de vista sóciohistórico, a origem da comunicação é o enunciado, e sua característica mais importante é que ele tem o potencial de resposta que facilita a criação do diálogo. Logo, a expressividade do enunciado se constitui na relação com outros enunciados, seguindo uma relação simbólica entre os falantes, já que ele é "pleno de tonalidades dialógicas, e sem levá-las em conta é impossível entender até o fim o estilo de um enunciado" (BAKHTIN, 2016, p.59), pois o "falante e compreendedor jamais permanecem cada um em seu próprio mundo; ao contrário, 
encontram-se num novo, num terceiro mundo, no mundo dos contatos; dirigem-se um ao outro, entram em ativas relações dialógicas" (BAKHTIN, 2016, p. 113).

Outrossim, Bakhtin (2003, p. 348) afirma que o monologismo "nega ao extremo, fora de si, a existência de outra consciência isônoma e isônomo-responsiva, de outro eu (tu) isônomo. No enfoque monológico (em forma extrema ou pura), o outro permanece inteiramente apenas objeto da consciência e não outra consciência." Nós podemos observar os traços de monologismo na distribuição desigual de papéis sociais nas salas de aula. Quando Bakhtin afirma que o monologismo "pretende ser a última palavra" (2003, p.348), ele aponta para um problema comum em nossas escolas: "(...) o sujeito que é cognoscente e domina a verdade ensina ao que não é cognoscente e comete erros, vale dizer, conhece a inter-relação entre o mestre e o discípulo e, consequentemente, apenas o diálogo pedagógico" (1997, p.81).

Logo, nessa relação, alguém que conhece a verdade ensina a alguém que não a tem ou que está errado. Em um ambiente escolar, isso se caracteriza por uma tendência ao uso de discurso autoritário, que "exige nosso reconhecimento incondicional, e não absolutamente uma compreensão e assimilação livre em nossas próprias palavras" (BAKHTIN, 2002, p.144). Por parte do docente, esse discurso pode se manifestar através de declarações que instruem o aluno a recitar diretamente de um livro didático ou a concordar com a posição expressa pelo professor, em vez de convidar os alunos a explicar seu próprio ponto de vista. Muitos professores tendem a ignorar as outras vozes e o que eles querem é transmitir seu conhecimento que é "concluído e surdo à reposta do outro, não o espera nem reconhece nele força decisiva" (BAKHTIN, 2003, p.348).

Aliás, com uma miríade de informações disponíveis nos meios digitais, parte dos professores poderia ser mais criativa em sua mediação, vinculando-a a práticas significativas e transformadoras, diferentemente daqueles que seguem práticas mais tradicionais, quando muitos podem simplesmente seguir o currículo escolar como uma questão de cronologia - em uma abordagem linear - e avaliar os alunos desconsiderando especificidades. Entretanto, a situação é mais desafiadora hoje. Incluindo a preparação, o planejamento e execução de aulas, professores, sobretudo da educação básica, tendem a lidar com várias funções adicionais, dentro e fora da sala, tais como: psicoeducador, assistente social, conselheiro, supervisor de 
turma, administrador de excursões de campo e mais ${ }^{2}$; predispondo a falta de tempo para um planejamento mais elaborado.

Em certos casos, soma-se também a pressão de desempenho pelos administradores da escola, onde um professor fica responsável pela porcentagem de vitórias da turma em olimpíadas ou em outras "competições de conhecimento", pelos indicadores de crescimento do aluno, e até mesmo pelos fatores disciplinares da turma em que leciona. Aqui a responsabilidade por uma série de funções, bem como por proporcionar novas abordagens criativas para atender às tendências educacionais e tecnológicas, possivelmente afetará o seu agir professoral.

Além do mais, a compreensão do conhecimento como um conceito fixo e estático que pode ser simplesmente transmitido aos estudantes é tão comum em nossas vidas, especialmente nas escolas, que talvez não surpreenda ver que o sistema tradicional de educação, onde o professor é elemento central responsável por ensinar e passar o conteúdo aos alunos, que serão avaliados por meio de provas e trabalhos, ainda seja o mais utilizado no Brasil $^{3}$. Nessa modalidade, aprender e estar preparado para a aula normalmente implica a memorização de conteúdos. O conhecimento é visto como algo definido e como um objetivo fixo, a maioria das dinâmicas em sala é voltada para o que já é conhecido e sabido. O papel dos estudantes sob tais circunstâncias se limita a lembrar o que outros, principalmente professores e livros didáticos, disseram, e não compreender as coisas ou construir algum conhecimento novo. ${ }^{4}$

Por sua vez, Paulo Freire (1996), que contribuiu fortemente para a abordagem da educação como "a prática da liberdade", explora muitos termos-chave significativos para uma

\footnotetext{
2 Por conta do contexto pandêmico do Coronavírus, as escolas tiveram que adotar novas tecnologias e ferramentas para se adequar as novas necessidades. Em muitos casos, não houve formação apropriada dos professores sobre como usar essas novas ferramentas. Muitos tiveram que descobrir por conta própria o quão eficaz são na utilização de tais recursos.

${ }^{3}$ Pesquisa realizada pelo portal "Melhor Escola", especializado em informações sobre educação, elencou as cinco principais metodologias de ensino no Brasil. Disponivel em: <https://www.melhorescola.com.br/artigos/cincometodologias-de-ensino-mais-utilizadas-no-brasil> acesso em 25 de julho de 2020.

${ }^{4}$ Oportuno dizer que aqui as percepções sobre os professores adeptos de concepções tradicionais de ensino não intencionam seu ostracismo ou rotulação como inferiores, nem destituí-los de seu status como profissionais da educação. Há, além dos já mencionados no artigo, outros fatores como as condições de trabalho ou sua formação inicial, que podem afetar e influenciar o seu ser e fazer docente.
}

Eutomia, Recife, 27(1): 293-306, Out. 2020 
alternativa ao modelo educacional tradicional, que ele chama de "educação bancária". Entre eles, o diálogo pode ser considerado como o conceito central: um fenômeno humano constituído, essencialmente, pela palavra, que possui duas dimensões intimamente relacionadas: ação e reflexão. "Não é no silêncio que os homens se fazem, mas na palavra, no trabalho, na ação-reflexão" (1996, p. 108). Freire não considera que o diálogo é simplesmente a interação entre pessoas para explorar o mundo juntos, é também um sinal de liberdade, igualdade e responsabilidade na descoberta e transformação do mundo de todo ser humano, o elemento humanizador e transformador da realidade.

Por isto, o diálogo é uma exigência existencial. $E$, se ele é o encontro em que se solidarizam o refletir e o agir de seus sujeitos endereçados ao mundo a ser transformado e humanizado, não pode reduzir-se a um ato de depositar ideias de um sujeito no outro, nem tampouco tornar-se simples troca de ideias a serem consumidas pelos permutantes. (...) É um ato de criação. Daí que não possa ser manhoso instrumento de que lance mão um sujeito para a conquista do outro. A conquista implícita no diálogo é a do mundo pelos sujeitos dialógicos, não a de um pelo outro (FREIRE, 1996, p. 91).

Ainda segundo Freire (1996), o verdadeiro diálogo não pode existir a menos que os parceiros se envolvam em amor, humildade, fé, confiança, esperança e pensamento crítico. Essa visão mostra que o diálogo revela não apenas a conexão positiva entre as pessoas, mas também o constante esforço para se transformar, bem como a realidade. Portanto, o diálogo se torna o sinal e o conceito central da verdadeira educação: "somente o diálogo, que implica um pensar crítico, é capaz, também, de gerá-lo. Sem ele não há comunicação e sem esta não há verdadeira educação" (1996, p. 80).

\section{Diálogo e Didática}

A teoria linguística baseada nos estudos saussurianos considera a palavra como um fenômeno interno ao indivíduo, psicológico, não tendo assim vínculo algum com o meio exterior, ou com a realidade material. Diz Saussure (1985, p 81) que "o laço que une o significante ao significado é arbitrário ou então, visto que entendemos por signo o total 
resultante da associação de um significante com um significado, podemos dizer simplesmente: o signo linguístico é arbitrário".

Destarte, os pressupostos saussurianos no Curso de Linguística Geral (1985), abordam o signo como a associação de um significado a um significante e, ao separar o plano da língua do plano da fala na constituição do sentido, os signos passam a se configurar como elementos isolados da realidade material, tornando-se inexistente o movimento dialético. Na perspectiva saussuriana, a língua é um meio de comunicação, mas não é concebida como uma via que permite a enunciação do outro no processo, ou seja, Saussure aborda "(...) a língua como se esta fosse monológica" (BAKHTIN, 2016 p. 118).

A escola que se formou nas sociedades da escrita também tem muitos desses traços. Por muitas vezes, essa escola acaba ensinando que o próprio mundo é absolutamente linear, que o conhecimento e a ciência devem ser assim: fragmentados, isolados, monológicos, buscando verdades únicas, absolutas e definitivas sobre uma realidade pouco conhecida.

Contudo, a constituição do sentido em um discurso não é apenas um produto da língua, ela reflete fatores extralinguísticos. O sentido se constrói na relação interna e externa, formando um todo significante que inclui linguagem verbal e não-verbal, o contexto em que se realiza, o suporte que o compreende, a forma de circulação, a interação com o seu exterior, o "outro" que está presente no "eu", entre outros elementos. De acordo com Volóchinov (2019, p.238), ao examinar formas concretas da enunciação, dos "atos de fala", já que "todo fenômeno pode ser melhor (sic) compreendido se observado no processo de seu surgimento e desenvolvimento", o enunciado se manifesta através de uma situação extraverbal e está estreitamente ligado com a situação que o provoca, isto é, se estiver desvinculado das condições reais da fala, ele perde sua significação.

Em "Marxismo e Filosofia da Linguagem", Volóchinov defende que todo enunciado real possui um sentido e as palavras assumem significações diversas em função do sentido do enunciado, resultando no fato de que o sentido da palavra é determinado por seu contexto e, no mais, "A palavra está sempre repleta de conteúdo e de significação ideológica ou cotidiana" (VOLÓCHINOV, 2017, p.177 - grifos do autor). O sentido de um enunciado decorre da interação de vozes ou perspectivas ideológicas abrangentes. Ademais, Volóchinov explicita que "a 
unidade real da linguagem (...) não é o enunciado isolado monológico, mas a interação de, pelo menos, dois enunciados, isto é, o diálogo" (2017, p. 244).

Outrossim, de acordo com Freire (1981), a principal função da educação é seu caráter libertador. Para ele, ensinar seria fundamentalmente, educar para a liberdade, a educação para o homem-sujeito: "ensinar não é transferir conhecimento, mas criar as possibilidades para a sua produção ou construção". (FREIRE, 1981, p.98). A partir desse entendimento, podemos afirmar que ensinar não é um mero repasse de informações, mas a transformação dos saberes do indivíduo, levando-se sempre em consideração o conhecimento prévio dos alunos. Portanto, as vivências de cada participante de uma aula enriquecem a mesma e, certamente, propiciam a construção de novos conhecimentos. Puente aponta que:

Quando um professor solicita a resposta de uma prova para a avaliação dos alunos, fica difícil superar o já inútil esquema tradicional de aula expositiva memorização - resposta, porque ainda não temos os novos parâmetros definidos, apenas estamos na procura deles, e talvez até nem sejam desejáveis tais padrões. (...) Se o professor ou professora anuncia a possibilidade de expressão da própria voz do aluno, tantas vezes antes apagada pelo monologismo pretensamente acadêmico, e aconselha não parafrasear os textos objeto de avaliação, resulta evidente que será a voz do aluno em toda sua extensão a que será pronunciada (se é que alguma voz pode ser estritamente individual) (...) a simples paráfrase (que habitualmente produz 0 sucesso do aluno tradicional) apenas implica repetição e em nada garante que esse discurso seja incorporado realmente ao acervo do aluno. (PUENTE, 1980, p.115)

Sendo assim, uma pedagogia fundamentada na abordagem dialógica convida os alunos a usar suas próprias palavras e expressar seus próprios julgamentos avaliativos. Nessa perspectiva, a ênfase é dada às respostas dos alunos, que são altamente valorizadas e validadas. Os alunos são colaboradores ativos e significativos do discurso em sala de aula junto com o professor. Aqui, o papel do professor, é mediar, discutir diretamente, sondar, prever e analisar as implicações da resposta do aluno, através de enunciados e não uma frase ou uma palavra isolada. "Tudo na vida é diálogo, ou seja, contraposição dialógica". (BAKHTIN, 1997, p. 45 - grifos do autor). A concepção de dialogismo está para a concepção de linguagem, considerada ato, pensamento, constituída na atmosfera do já dito. Todo enunciado considera e se direciona ao outro, abrindo várias possibilidades de campo de estudo e interferência nas 
dinâmicas da sala de aula. "Não há diálogo sem a construção de recursos expressivos, através dos quais pensamentos são organizados e expostos, compreendidos e modificados" (GERALDI, 2005, p. 14).

A educação escolar em sua realidade empírica é constitutivamente dialógica, considera os saberes do outro: os seus saberes prévios, do senso comum, e o ouve atentamente. Logo, uma proposta didática, pautada em uma relação dialógica, favorece a construção do conhecimento, alcançado mediante uma elaboração pessoal, em articulação com diferentes ações do sujeito e o seu meio, na solução de problemas a respeito de o que ensinar, para que $(m)$ ensinar e como ensinar, conectando os tópicos de aprendizagem em sala com os que os alunos já conhecem.

Conjugada com os estudos de gênero, podendo estabelecer interligações entre esferas do oral e do escrito, essa questão coloca desafios importantes para os docentes, exige a problematização da realidade. Um esforço coletivo e recíproco, com ideias compartilhadas entre os participantes, e de apoio, com esses participantes se incentivando a contribuir e valorizar todas as contribuições. Não se trata simplesmente de reproduzir ou repetir um discurso: "a verdade não nasce nem se encontra na cabeça de um único homem; ela nasce entre os homens, que juntos a procuram no processo de sua comunicação dialógica" (BAKHTIN, 1997, p. 111 - grifos do autor).

\section{Conclusão}

Em uma concepção de educação transformadora, a abordagem dialógica vai ao encontro das preocupações com a desconstrução do poder do professor como único "conhecedor e senhor da informação", abrindo espaço para uma educação com várias vozes. Este trabalho buscou analisar como os princípios da abordagem dialógica podem se configurar como orientadores de uma postura pedagógica que busca uma educação que prima pela interação verbal entre sujeitos.

O enunciado tem seus significados e sentidos construídos na relação entre os sujeitos. A compreensão que o sujeito tem de si se constitui através do olhar e da palavra do outro. Portanto, a linguagem sempre requer interpretação com base em fatores linguísticos e 
extralinguísticos, já que compreender a fala de alguém significa compreender seu pensamento, seu posicionamento, seus valores, sua ideologia. É o processo dialógico, e não o monológico, que possibilita a constituição do sentido que vem a ser parte integrante da condição humana e um modo de relacionar a vida dos aprendizes ao movimento de interpretação das coisas do mundo.

Considerando a educação como atividade social, mediada pelo diálogo, o dialogismo nos escritos de Bakhtin e de Volóchinov permite uma série de inter-relações com, a realidade, a ideologia, a interação, o contexto, a compreensão e a significação. O docente que deseja se fundamentar nesses pressupostos deve assumir uma posição de mediador das atividades de sala de aula, não impondo suas posições, mas discutindo-as, trabalhando por meio do diálogo, contribuindo para a construção de conhecimentos relevantes para o exercício da cidadania plena, bem como orientando os participantes a estender e estabelecer vínculos dentro de suas próprias vivências. Do mesmo modo, é necessário que professores possam dispor de tempo e espaço para (re)definir seus esforços, viabilizando a redução do estresse da gestão da sala de aula, e garantindo que eles estejam mais bem equipados e preparados para atender às necessidades de uma população de estudantes em constante mudança.

\section{Referências}

BAKHTIN, M. Problemas da poética de Dostoiévski. 2 ed. revista Trad. Paulo Bezerra. Rio de Janeiro: Forense Universitária, 1997. [1963]

BAKHTIN, M. O discurso no Romance. In: BAKHTIN, M. Questões de literatura e de estética: a teoria do romance. 5 ed. Trad. Aurora Fornoni Bernardini et al.. São Paulo: Hucitec, 2002.

BAKHTIN, M. Reformulação do livro sobre Dostoiévski. In: BAKHTIN, M. Estética da criação verbal. Introdução e tradução do russo Paulo Bezerra. 4. ed. São Paulo: Martins Fontes, 2003.

BAKHTIN, M. Os gêneros do discurso. Organização, tradução, posfácio e notas de Paulo Bezerra. São Paulo: Editora 34, 2016.

FREIRE, Paulo. Educação como Prática da Liberdade. Rio de Janeiro: Paz e Terra, 1981.

Eutomia, Recife, 27(1): 293-306, Out. 2020 
FREIRE, Paulo. Pedagogia do Oprimido. São Paulo: Paz e Terra, 1996.

GERALDI, João W. Paulo Freire e Mikhail Bakhtin: O encontro que não houve. In: CORTESÃO, Luíza et al. Diálogos através de Paulo Freire. Colecção Querer Saber 1. Porto: Edição Instituto Paulo Freire de Portugal e Centro de Recursos Paulo Freire da FPCE, 2003/2004, p.37-52.

GERALDI, João W. A linguagem em Paulo Freire. Educação, Sociedade \& Culturas, n. 23, 2005, p.7-20.

PUENTE, M. de la. Abordagem centrada na pessoa e a educação. In: PENTEADO, W. M. D. (org). Psicologia e Ensino. São Paulo: Papel livros, 1980, p. 101-117.

SAUSSURE, Ferdinand. Curso de Linguística Geral. São Paulo: Cultrix, 1985.

VOLÓCHINOV, V. Marxismo e filosofia da linguagem (problemas fundamentais do método sociológico na ciência da linguagem). Tradução, notas e glossário de Sheila Grillo e Ekaterina Vólkova Américo; ensaio introdutório de Sheila Grillo. São Paulo: Editora 34, 2017.

VOLÓCHINOV, Valentin. A palavra na vida e a palavra na poesia: ensaios, artigos, resenhas e poemas. Organização, tradução, ensaio introdutório e notas: Sheila Grillo e Ekaterina Vólkova Américo. São Paulo: Editora 34, 2019.

\footnotetext{
' Júlio César Brandão é professor de língua inglesa da educação básica, técnica e tecnológica do Colégio de Aplicação da Universidade Federal de Pernambuco (CAp - UFPE). Doutorando em Ciências da Linguagem da Universidade Católica de Pernambuco (UNICAP). Possui graduação em Licenciatura em Letras (português e inglês) pela UFPE (2006), especialização em linguística aplicada ao ensino de língua inglesa pela Faculdade Frassinetti do Recife (FAFIRE) (2010) e Mestrado em Ciências da Linguagem pela UNICAP (2016).

i" Dóris de Arruda da Cunha é professora titular da Universidade Federal de Pernambuco (UFPE) (aposentada), professora da Universidade Católica de Pernambuco (UNICAP) e Pesquisadora do CNPq. Possui licenciatura em Letras (português e francês) pela UFPE (1983), DEA en Linguistique - Université de Paris V (Rene Descartes) (1986), doutorado em Ciências da Linguagem - Université Paris Descartes (1990), e pós-doutorado na Université de Paris III - Sorbonne Nouvelle e na PUC-SP (2009-2010). Fez estágio de desenvolvimento de projeto de pesquisa supervisionado por Frédéric François (2014), da Université Paris Descarte (Paris V) e pós-doutorado na Universidade Federal do Paraná (UFPR) (2019).
}

Eutomia, Recife, 27(1): 293-306, Out. 2020 